\title{
Laboreal
}

Volume $8 \mathbf{N}^{\circ} 1$ | 2012

Género, Atividades e Saúde

\section{Gestão dos tempos e do percurso profissional : estratégias das mulheres em profissões definidas no masculino}

Gestión de los tiempos y del recorrido profesional : las estrategias de las mujeres en profesiones definidas en masculinoGestion des temps et du parcours professionnel : stratégies des femmes au sein de professions définies au masculin Time and career management : strategies of women in typically male professions

\section{Sónia Nogueira e Joana Castelhano}

\section{(2) OpenEdition}

\section{Journals}

\section{Edição electrónica}

URL: http://journals.openedition.org/laboreal/7082

DOI: $10.4000 /$ laboreal.7082

ISSN: 1646-5237

\section{Editora}

Universidade do Porto

\section{Refêrencia eletrónica}

Sónia Nogueira e Joana Castelhano, « Gestão dos tempos e do percurso profissional : estratégias das mulheres em profissões definidas no masculino », Laboreal [Online], Volume $8 N^{0} 1$ | 2012, posto online no dia 01 julho 2012, consultado o 08 outubro 2019. URL : http://journals.openedition.org/laboreal/ 7082 ; DOI : 10.4000/laboreal.7082

Este documento foi criado de forma automática no dia 8 outubro 2019

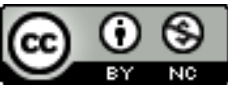

Laboreal está licenciado com uma Licença Creative Commons - Atribuição-NãoComercial 4.0 Internacional. 


\section{Gestão dos tempos e do percurso profissional : estratégias das mulheres em profissões definidas no masculino}

Gestión de los tiempos y del recorrido profesional : las estrategias de las mujeres en profesiones definidas en masculinoGestion des temps et du parcours professionnel : stratégies des femmes au sein de professions définies au masculin Time and career management : strategies of women in typically male professions Sónia Nogueira e Joana Castelhano

\section{NOTA DO EDITOR}

Manuscrito recebido em : Março/2012

Aceite após peritagem : Junho/2012

\section{Introdução}

1 O tempo dita as regras de toda a actividade humana, constituindo a modalidade de regulação da sua existência (Alaluf, 2000). Este factor é de uma importância central na análise económica e social e divide-se, essencialmente, em tempo de trabalho e tempo de não trabalho (Martinez, 2010). Nesta dicotomia, o tempo de trabalho prevalece sobre os outros tempos de vida e, nesse sentido, acaba por os regular. Contudo, mais do que a prevalência de uma sobre a outra, é o interface entre estas diferentes temporalidades que adquire um maior sentido quando se estudam as actividades de trabalho marcadas por organizações temporais baseadas no princípio de uma disponibilidade total para o trabalho. É o caso das profissões de motorista e de polícia - que tomaremos como 
referência neste artigo a partir de dois estudos de caso - profissões maioritariamente desempenhadas por homens, em processo de feminização, mas que mantêm modos de organização do trabalho eminentemente masculinos. Os horários de trabalho exigentes e penosos colocam dificuldades adicionais às mulheres nestes contextos profissionais pelas suas maiores responsabilidades a nível familiar e doméstico e reflectem um uso sexuado do tempo, que surge como um dos pontos-chave de (des)igualdade entre homens e mulheres (Silvera, 2005).

2 Neste artigo, tomando como referência os dois estudos de caso no sector das forças de segurança e no sector dos transportes rodoviários de passageiros, reflectimos sobre o factor tempo à luz dos questionamentos que as mulheres fazem em relação à organização temporal do trabalho e das estratégias que empreendem para gerir eficazmente os seus tempos de trabalho e de vida - que acabam por corresponder a uma gestão temporal quotidiana mas também a opções ao nível do percurso profissional e da gestão de carreira.

\section{O tempo e o trabalho}

3 O tempo é um factor estruturante na vida dos indivíduos e das sociedades e, no que ao trabalho diz respeito, "intervém em todas as dimensões da relação salarial, nas formas contratuais da mobilização do trabalho, nas modalidades organizacionais de uso da força de trabalho e na troca salarial" (Martinez, 2010, p. 8, tradução livre).

4 Segundo Maruani (2007), os tempos de trabalho contribuem para o desenho de novas configurações nas relações sociais, demarcando categorias de trabalhadores: os que têm isenção de horário e os que vivem condicionados por tempos impostos, os que têm um tempo de trabalho regular e regulado e os que trabalham com horários desfasados ou imprevisíveis. E são eles também um dos elementos essenciais de distinção entre "empregos femininos" e "empregos masculinos", que contribuem para a constituição de diferenças e de desigualdades no trabalho. Numa altura em que inúmeras alterações se processam no mercado de trabalho, com implicações nos tempos, é pertinente reflectir sobre estas evoluções diversas e contraditórias : a diminuição do tempo de trabalho que surge em paralelo com a intensificação dos constrangimentos temporais, uma diversificação simultânea a um fraccionamento dos tempos de trabalho, a homogeneização da presença feminina e masculina nas actividades de trabalho mas com estatutos de emprego diferenciados, em resultado de uma distinta disponibilidade para o trabalho (Maruani, 2007). De facto, a flexibilização dos tempos de trabalho como uma tendência geral do mercado - em que o trabalho deixa de ser medido em tempo e passa a sê-lo em função da concretização dos objectivos definidos e da demonstração de resultados - contribui para uma crescente invasão dos tempos dedicados à vida extraprofissional (Martinez, 2010).

5 Segundo Alaluf (2000), no período pré-industrial, o trabalho confundia-se com o tempo dedicado à vida pessoal e familiar - a actividade profissional de agricultores ou artesãos não se distinguia do tempo dedicado à família, em casa; com a industrialização, o trabalho assume um tempo aparte e o trabalhador é remunerado pelo tempo despendido a trabalhar para outrem, sendo o tempo no trabalho mais importante do que o conteúdo do trabalho. É nesta altura que se delimitam claramente o tempo de trabalho e o tempo de não trabalho. Esta divisão essencial corresponde a uma relação de prevalência do primeiro sobre o segundo e revela o carácter estruturante da 
actividade profissional na vida dos sujeitos - ela prescreve não só os tempos de trabalho mas também os tempos de não trabalho (Alaluf, 2000). Todavia, mais do que esta "superioridade", quando se estuda o ser humano trabalhador, importa considerar a inter-relação entre estas diferentes temporalidades - efectivamente, "o uso do tempo define-se pelo cruzamento de uma pluralidade de constrangimentos temporais, quer do trabalho, quer da vida privada" (Martinez, 2010, pp. 74, tradução livre) e a consideração dos tempos dos trabalhadores não pode ser feita apenas pela análise da organização dos tempos de trabalho, mas também pela articulação com os outros tempos de vida, isto é, pela forma como os horários de trabalho criam condições ou dificultam uma conciliação com a vida pessoal e familiar.

\subsection{A articulação da vida profissional com a vida pessoal e familiar}

6 Se é verdade que diversas mudanças no mercado de trabalho, como a desregulação do mercado de trabalho, a globalização e as pressões competitivas crescentes para reduzir os custos e alcançar maiores margens de lucro (Rapoport \& Bailyn, 1998, conforme citado por Burchielli, Bartram \& Thanacoody, 2008), têm contribuído para as dificuldades de conciliação, também o processo de feminização das profissões levantou um conjunto de questões relacionadas com a gestão dos tempos entre responsabilidades profissionais, domésticas e familiares (Perista, 1999).

7 Durante muitos anos, os homens estiveram maioritariamente dedicados à vida profissional e as mulheres, à esfera privada, o que levou a que os tempos de trabalho fossem pensados com o pressuposto de uma disponibilidade total para o trabalho. De facto, o trabalho é visto como uma condição para o exercício normal do papel familiar para o homem mas não para a mulher. Este foi um cenário que se alterou com o movimento de entrada das mulheres no mercado de trabalho (Martinez, 2010) - passa a ser necessário organizar os tempos de trabalho de modo a permitir dar resposta a uma dupla exigência de disponibilidade das mulheres. Isto tendo em conta que o ingresso na esfera laboral não foi acompanhado na mesma proporção pelo ingresso dos homens na esfera privada (Suard, 2003) - os dados relativos ao uso do tempo apresentados por Hirata, Lombardi e Maruani (2008) mostram que, em média, as mulheres trabalham menos 95 minutos por semana que os homens mas consagram 131 minutos a mais do que estes às tarefas domésticas. Esta torna-se uma das razões pela qual as mulheres continuam a ser as principais afectadas pela problemática da conciliação entre o trabalho doméstico e o trabalho remunerado (Vogel, 2003).

8 Para além disto, o ajustamento dos horários profissionais e domésticos é ainda mais desafiante quando é necessário regular os constrangimentos associados a horários irregulares, existentes em diversas actividades de trabalho. Estes apresentam dificuldades suplementares e exigem um esforço de gestão dos vários tempos de vida ainda mais amplo e complexo (Prévost \& Messing, 2001) e obrigam à mobilização de alguns tipos específicos de estratégias, tais como a organização individual rígida do sono e das refeições ou a opção por um horário atípico de forma a cuidar dos filhos durante o dia ou nos fins-de-semana (Barthe e Abbas, 2009). Uma outra estratégia frequentemente apontada é a de flexibilização de horários de trabalho, deixada sobretudo a cargo do trabalhador, que se depara com a necessidade de gerir as responsabilidades profissionais, pessoais e familiares (Burchielli, Bartram \& Thanacoody, 2008). Contudo, esta não é uma estratégia isenta de consequências, visto 
que os acordos de horários flexíveis sugerem que o foco é colocado nas escolhas individuais relacionadas com o uso do tempo, o que leva a questionar o recurso à flexibilidade como instrumento de conciliação. Na definição das preferências em termos de horários de trabalho, as próprias considerações que são feitas variam entre homens e mulheres - as mulheres têm mais em conta as responsabilidades domésticas e familiares e os homens, o lazer ou actividades periféricas (Prévost \& Messing, 2001).

Os tempos e temporalidades das mulheres apresentam, assim, características específicas, que exigem um esforço de gestão físico, psíquico e emocional quase indistinto e que, muitas vezes se torna invisivel, sobretudo no que diz respeito ao trabalho doméstico (Messing, 2000 ; Perista, 2002 ; Prévost \& Messing, 2001), não dando conta dos custos físicos e psicológicos inerentes a este trabalho não remunerado. Para além disso, a conciliação dos imperativos do trabalho e da carreira com as responsabilidades familiares pode também constituir-se como um custo para a carreira e o percurso profissional das mulheres, como um obstáculo à aquisição das competências valorizadas na progressão profissional, perpetuando e reforçando a segregação (Grönkvist \& Lagerlöf, 2000).

\section{As mulheres e o mundo do trabalho}

10 Apesar de a mulher sempre ter trabalhado, nomeadamente na agricultura, a revolução industrial é frequentemente considerada como um marco importante na entrada das mulheres no mercado de trabalho, visto que foi durante esta altura que a mulher trabalhadora ganhou maior destaque (Scott, 1994). Contudo, continuou a ser vista como uma trabalhadora de segunda ficando, na larga maioria dos casos, confinada a empregos de baixos salários e não especializados, que reflectiam a prioridade das suas obrigações domésticas e maternais sobre as responsabilidades profissionais. $\mathrm{O}$ ingresso em massa das mulheres no mercado de trabalho acontece sobretudo durante a segunda metade do século XX.

11 No que respeita a Portugal, nos anos cinquenta do século passado, as mulheres estavam ainda, na larga maioria dos casos, limitadas à esfera privada, acumulando as funções de esposa e de mãe, com excepção dos meios rurais, onde as mulheres eram igualmente responsáveis pelo trabalho agrícola (Silva, 1983). Na década de 60 verifica-se um aumento da procura de emprego por parte das mulheres, justificado pela emigração, o êxodo rural, a mobilização militar e a guerra colonial, tendo-se revestido de um carácter de inevitabilidade social e assumindo-se como um recurso familiar (Lopes \& Perista, 2010). $O$ ingresso das mulheres ocorreu no sector secundário, mas também no sector terciário e em funç̃oes que não eram mais do que o prolongamento das suas tarefas domésticas (eg. serviços de apoio doméstico, educação e saúde, ou administração pública) (Lopes \& Perista, 2010).

12 Com o fim do período do Estado Novo, foram dados os primeiros passos para a eliminação da discriminação contra as mulheres, através da elaboração da Regulamentação do Trabalho Feminino (Monteiro, 2010). Em 1976, na Constituição Portuguesa é assegurada "a igualdade de oportunidades na escolha da profissão ou género de trabalho, bem como as condições para que não seja vedado ou limitado, em função do sexo, o acesso a quaisquer cargos, trabalho ou categorias profissionais". (Constituição da República Portuguesa, artº $^{\circ} 8^{\circ}$ ). 
13 Nas décadas de 80 e 90, o emprego feminino continua a ser caracterizado por maiores graus de precariedade e probabilidade de desemprego, bem como por propiciar experiência e formação profissionais menos qualificantes (Lopes \& Perista, 2010). Na segunda metade da década de 80 paralelamente a outras iniciativas de incentivo ao emprego feminino, foram sendo introduzidas, de forma gradual, medidas dirigidas à integração de mulheres em profissões tradicionalmente masculinas, através da criação de um "Núcleo para o Emprego Feminino" no Instituto de Emprego e Formação Profissional.

\subsection{0 processo de feminização de profissões tipicamente masculinas}

140 mundo do trabalho não é uma realidade homogénea quanto à distribuição por género, na medida em que "homens e mulheres não exercem as mesmas profissões, não trabalham nos mesmos sectores de actividade e são colocados em situações de trabalho diferentes" (Grozelier, 1987, p. 266, tradução livre). De facto, apesar da já referida crescente entrada das mulheres no mundo do trabalho, existem ainda sectores onde a presença masculina é quase exclusiva ou, pelo menos, maioritária, e que justificam a denominação de "profissão tipicamente masculina", ou seja, uma profissão em que as mulheres não atingem um terço do número total de trabalhadores (Portaria n.. 1212 / 2000 de 26 de Dezembro).

O processo de feminização destes contextos profissionais faz-se através de inúmeras mudanças - para as mulheres que passam a desempenhar uma actividade de trabalho que até aí lhes estava "vedada", mas também para os homens que já a desempenhavam e que não ficam indiferentes a esta "mixigenação". Aliás, de acordo com Kergoat (1993), há algo que se reconstrói com a integração de mulheres em empregos maioritariamente masculinos

16 Para as primeiras, o facto de terem de encontrar o seu lugar e construir o seu percurso nestas profissões exige a mobilização de estratégias de integração no colectivo de trabalho ou de demonstração das suas competências específicas. Estas mulheres confrontam-se com dificuldades mais marcadas do que aquelas que desenvolvem a sua actividade profissional em universos mistos, na medida em que, face à sua entrada, diversos mecanismos individuais e colectivos de defesa são postos em prática pelos homens (Pfefferkorn, 2008), o que origina a que elas, não raras vezes, se sintam como "intrusas" (Lacomblez, 2008).

17 Se, por um lado, a inserção das mulheres neste tipo de profissões lhes coloca alguns desafios e atribui à sua actividade certas particularidades, por outro lado, acaba por contribuir para a evolução de debates de valores e das relações com o trabalho (Lacomblez, 2008). Trata-se de um ingresso que gera controvérsias e questionamentos, que perturba a ordem estabelecida pelos homens e por identidades profissionais construídas sobre princípios eminentemente masculinos (Scheller, 1996). Assiste-se a um re-pensar e a uma re-definição de regras uma vez que as mulheres levam os homens questionar as configurações da organização do trabalho e a reflectir, muitas vezes pela primeira vez, sobre questões relacionadas, por exemplo, com os horários de trabalho ou o conflito trabalho-família que são, habitualmente, levantadas por elas. 


\section{Dois estudos de caso em profissões tipicamente masculinas}

18 Os estudos de caso aqui apresentados foram desenvolvidos no sector dos transportes rodoviários de passageiros e no sector das forças de segurança, na área metropolitana do Porto, enquadrados num projeto de investigação que visava o estudo do processo de feminização de profissões tipicamente masculinas.

19 Em termos metodológicos, em coerência com a tradição científica da ergonomia da actividade, em que nos inscrevemos, foi feita uma análise ergonómica do trabalho dos motoristas e dos polícias, com o intuito de melhor conhecer e compreender a sua actividade, as condições em que é exercida e os constrangimentos com que se confrontam. Os dados obtidos desta forma foram complementados através do recurso a um inquérito que aborda as relações entre a saúde e o trabalho - Inquérito Saúde e Trabalho (2007) (Barros-Duarte, Cunha \& Lacomblez, 2007) -, a entrevistas semiestruturadas com os participantes e a consulta documental.

As questões de investigação colocadas inicialmente - nomeadamente relacionadas com os constrangimentos e desigualdades entre homens e mulheres que ainda persistem nestes contextos profissionais ou com os questionamentos que emergem com a feminização, ao nível das condições e da organização do trabalho - acabaram por revelar a importância do factor tempo nestas duas actividades. As características das próprias actividades de trabalho, como a necessidade de prestação do serviço durante as 24 horas do dia, tema que iremos desenvolver mais à frente, assim como os constrangimentos e as estratégias apontadas pelos participantes no decorrer da pesquisa, contribuíram para que a organização temporal do trabalho assumisse um papel central e novas questões fossem colocadas. Como gerem estes profissionais os seus tempos de trabalho ? Considerando os desafios adicionais das mulheres ao nível da conciliação com a vida pessoal e familiar, que estratégias são utilizadas especificamente pelas mulheres? Que implicações têm estas estratégias de gestão ? É o que tentaremos responder de seguida.

\subsection{As mulheres motoristas : uma gestão "experimentada" dos horários de trabalho}

21 Durante muitos anos, a profissão de motorista esteve reservada aos homens e, em Portugal, apenas na década de 90 , se iniciou a integração de mulheres. $\mathrm{Na}$ área metropolitana do Porto, onde foi desenvolvida esta pesquisa, esta entrada ocorreu no ano de 2000 e, em 2005 (data a que correspondem os únicos dados disponíveis) as mulheres constituíam apenas 1,4 \% dos efectivos de motoristas (Projecto Volante XXI, 2005). Deste modo, apesar da progressiva integração de mulheres, ser motorista de transportes públicos permanece tradicional e culturalmente conotado como uma actividade tipicamente masculina, associada a gestos, palavras, atitudes e saberes-fazer particularmente detidos ou assumidos por homens (Scheller, 1996) e onde as condições e a organização do trabalho são pensadas para o trabalhador masculino (Copsey \& Schneider, 2008; Schneider \& Irastroza, 2011). Este facto resulta na existência de algumas particularidades na actividade das mulheres motoristas, relacionadas, 
nomeadamente, com a integração no colectivo de trabalho, a relação com colegas e passageiros (Cunha, Nogueira \& Lacomblez, 2012) ou as questões de saúde.

No que aos tempos de trabalho diz respeito, e como diversas pesquisas já deram a perceber (Cunha \& Gil Mata, 2005 ; Cunha, 2012), os tempos dos motoristas afastam-se de tal modo da norma, que poderão concentrar em si mesmos a essência das dificuldades e dos prazeres da profissão (Scheller, 1996, 2009). Neste sector - dos transportes rodoviários de passageiros - os tempos de trabalho não parecem ser mais do que "uma variável dependente, um produto corolário das flutuações da actividade" (Martinez, 2010, p.7, tradução livre). De facto, critérios como a necessidade de prestação do serviço durante as 24 horas do dia ou de ajustamento da oferta do serviço à procura por parte dos passageiros, com as suas variantes ao longo do dia e ainda nos dias úteis e de fim-de-semana condicionam a configuração dos horários de trabalho e determinam a atipicidade e penosidade que os caracterizam. E, se esta situação sempre se verificou, nos anos mais recentes, alterações globais no mercado de trabalho que levaram, por exemplo, a uma flexibilização dos horários ou ao aumento do trabalho em part-time ou ao fim-de-semana, nomeadamente no sector dos serviços (Martinez, 2010), fizeram com que fossem equacionadas novas necessidades a que os transportes públicos deveriam dar resposta. Esta alteração da necessidade do serviço de transporte obriga também a mudanças nos horários de trabalho de quem o presta, tornando-os mais dispersos e penosos.

23 Este estudo, que contou com uma amostra de 32 motoristas - 16 homens e 16 mulheres - de duas empresas de transportes colectivos urbanos, da área metropolitana do Porto, permitiu confirmar a organização temporal da sua actividade como a maior fonte de constrangimentos, tanto para as mulheres como para os homens, mas com diferentes sentidos e custos para uns e outros.

\subsubsection{A organização temporal da actividade dos motoristas}

Os horários de trabalho dos motoristas estudados apresentam uma configuração muito particular. Características como a irregularidade/variabilidade, atipicidade e imprevisibilidade dos horários, a dessincronização em relação aos tempos sociais e familiares (trabalho ao fim-de-semana, por exemplo) ou um tempo de ocupação elevado (seja em horas de condução ou não), justificam a sua penosidade e revelam uma complexidade fora do comum.

Antes de mais, existem diversos tipos de serviços e de estatuto de motorista, que correspondem a diferentes horários, mais ou menos favoráveis, e a permanência num estatuto ou transição para um mais favorável é determinada pela antiguidade do motorista na empresa.

Quando iniciam a sua actividade, os motoristas podem escolher entre um de dois estatutos - "encaixado em fora-de-regras" ou "escalado" - que variam, sobretudo, ao nível dos serviços desempenhados e da antecedência com que têm conhecimento deles. No estatuto "encaixado em fora-de-regras", o motorista desempenha apenas serviços "fora-de-regras" - serviços com um intervalo de duração de duas a cinco horas e meia, e com um tempo de ocupação que pode ser de 14 horas, que são considerados os serviços mais penosos, devido ao longo intervalo e ao tempo de ocupação elevados - e têm conhecimento deles com meses de antecedência. Os motoristas "escalados" desempenham todos os serviços: "seguidos" (serviços sem intervalos, que ocupam 
apenas uma manhã, uma tarde, a noite ou a madrugada), "em duas etapas" (serviços realizados em duas partes, com um intervalo de duração inferior a duas horas) e "forade-regras". Por um lado, os escalados, têm a vantagem de realizar os serviços mais penosos, os "fora-de-regras" de forma mais esporádica; contudo, têm a desvantagem de apenas terem conhecimento do serviço a realizar com dois dias de antecedência.

Com a permanência na actividade, será possível aceder ao estatuto que corresponde ao topo da carreira, o de "encaixado" - estes motoristas desempenham apenas serviços "seguidos" e "em duas etapas" e sabem com meses de antecedência o horário dos serviços que irão realizar. Esta informação está resumida e esquematizada na tabela que se segue (cf. Tabela 1).

Tabela 1 - Estatuto dos motoristas, em função do tipo de serviços e horários praticados

\begin{tabular}{|l|l|l|l|}
\hline & $\begin{array}{l}\text { Encaixado } \\
\text { "Fora-de- } \\
\text { regras" }\end{array}$ & Escalado & Encaixado \\
\hline Tipo de serviços & $\begin{array}{l}\text { "Fora-de- } \\
\text { regras" }\end{array}$ & $\begin{array}{l}\text { Seguidos, em duas etapas e } \\
\text { "fora-de-regras" }\end{array}$ & $\begin{array}{l}\text { Seguidos e em duas } \\
\text { etapas }\end{array}$ \\
\hline $\begin{array}{l}\text { Antecedência do conhecimento } \\
\text { dos serviços }\end{array}$ & Meses & 2 dias & Meses \\
\hline
\end{tabular}

28 A possibilidade de optar por determinado estatuto na empresa e, consequentemente, por determinadas configurações de horários é relativamente recente. Há uns anos atrás, a permanência nestes estatutos menos favoráveis era imposta a motoristas recém-admitidos na empresa e encarada como um "período de transição" até que surgisse uma oportunidade de integração numa escala de serviços, com um consequente abandono de algumas exigências associadas a este tipo de serviços. No entanto, a pesquisa com as mulheres tornou saliente o facto destes estatutos e, nomeadamente, os serviços "fora-das-regras" não serem, hoje em dia, desempenhados somente por motoristas no início da carreira, nem por um "período de transição". Efectivamente, estes períodos de permanência são agora mais longos, reflexo de uma política de não contratação de novos motoristas e de redução de algumas regalias que eram adquiridas no topo da carreira (Cunha \& Gil Mata, 2005), que acabou por contribuir para a generalização de estatutos precários deste tipo, com implicações na progressão na carreira.

Este facto é particularmente importante se considerarmos a situação das mulheres na profissão : em resultado de uma entrada mais tardia na profissão, todas as mulheres permanecem há vários anos nos estatutos mais penosos. Enquanto muitos homens desempenharam a sua actividade com a perspectiva de rapidamente evoluir para estatutos mais favoráveis, nenhuma das mulheres terá a possibilidade de usufruir de uma progressão nos mesmos moldes.

A precariedade associada a estes estatutos passou a ser "característica" da actividade pela penosidade de horários com um tempo de ocupação excessivo ou pela falta de planeamento da sua actividade, que compromete frequentemente os períodos de 
descanso, as refeições ou a organização da vida extra-profissional - e acaba por exigir uma avaliação, ponderação e gestão dos estatutos que não existia anteriormente.

\subsubsection{Homens e mulheres motoristas : diferentes formas de gestão dos tempos de trabalho e dos tempos de vida}

A variedade de horários e serviços dota a organização temporal do trabalho dos motoristas de uma complexidade pouco comum que exige uma ponderação e uma gestão nem sempre fácil ou unânime entre eles, no sentido em que não são claras as vantagens de um e outro estatuto. Quer mulheres, quer homens, na escolha dos estatutos, ponderam critérios de vária natureza, como as características dos horários associados a cada estatuto, a vida extra-profissional, o local de residência ou as consequências para a saúde.

Todavia, nesta pesquisa, verificou-se que, para além desta ponderação, no caso das mulheres, a gestão do tempo exige a experimentação das diversas opções para que se consiga perceber quais as vantagens e desvantagens dos estatutos. A passagem pelos dois estatutos é comum a muitas das mulheres participantes - enquanto os homens se mantiveram, quase sempre, numa primeira opção, as mulheres foram alternando entre estatutos e horários de modo a conseguirem perceber qual o que melhor se adequa. Esta tendência é visível na tabela que se segue (Tabela 2), onde são apresentados alguns exemplos dos percursos ao nível da permanência e transição entre estatutos de motorista.

Tabela 2 - Percurso de alguns dos motoristas ao nível da permanência nos estatutos

\begin{tabular}{|c|c|c|c|c|}
\hline Motorista & Antiguidade na empresa (em anos) & Percurso & & \\
\hline Mulher1 & 10 & $\begin{array}{l}\text { Escalada } \\
4 \text { anos }\end{array}$ & $\begin{array}{l}\text { Encaixada } \mathrm{FR}^{*} \\
3 \text { anos }\end{array}$ & Escalada \\
\hline Mulher2 & 10 & $\begin{array}{l}\text { Escalada } \\
4 \text { anos }\end{array}$ & $\begin{array}{l}\text { Encaixada } \mathrm{FR}^{*} \\
1 \text { ano }\end{array}$ & Escalada \\
\hline Mulher3 & 2 & $\begin{array}{l}\text { Encaixada } \mathrm{FR}^{*} \\
1 \text { ano }\end{array}$ & Escalada & \\
\hline Mulher4 & 2 & $\begin{array}{l}\text { Escalada } \\
4 \text { meses }\end{array}$ & Encaixada $\mathrm{FR}^{*}$ & \\
\hline Mulher5 & 1 & $\begin{array}{l}\text { Escalada } \\
1 \text { mês }\end{array}$ & Encaixada $\mathrm{FR}^{*}$ & \\
\hline Homem1 & 12 & $\begin{array}{l}\text { Escalado } \\
8 \text { meses }\end{array}$ & Encaixado & \\
\hline Homem2 & 9 & $\begin{array}{l}\text { Escalado } \\
9 \text { meses }\end{array}$ & Encaixado $\mathrm{FR}^{*}$ & \\
\hline
\end{tabular}




\begin{tabular}{|l|l|l|l|l|l|}
\hline Homem3 & 8 & $\begin{array}{l}\text { Escalado } \\
6 \text { meses }\end{array}$ & Encaixado FR* & & \\
\hline Homem4 & 2 & Encaixado FR & & & \\
\hline Homem5 & 1 & Encaixado $\mathrm{FR}^{*}$ & & & \\
\hline
\end{tabular}

*"Encaixado/a em fora-de-regras"

Vemos, por exemplo, que as duas mulheres mais antigas na empresa iniciaram a sua actividade no estatuto de "escalada", transitaram para o de "encaixada em fora-deregras" e regressaram ao de "escalada"; enquanto os homens mais antigos apenas alteraram uma vez o seu estatuto.

De seguida, apresentam-se três excertos, de três mulheres motoristas que referem diferentes motivos que sustentam as suas opções :

"Como eu estava cansada de andar escalada e fazer os piores fora-das-regras, pensei "Não, se faço os piores, também vou fazer os melhores" e pedi para encaixar [em "fora-de-regras"] e andei 3 anos a levantar todos os dias às $5 \mathrm{~h}$, $6 \mathrm{~h}$ da manhã e a chegar a casa às $18 \mathrm{~h}, 19 \mathrm{~h}, 20 \mathrm{~h}$. Cheguei ao fim de 3 anos e estava a dar em louca, quase não tinha vida pessoal, porque nós aqui temos pouca vida própria e a fazer estes serviços, pior ainda. Deixei de dormir, comecei a deixar de dormir, tinha o sistema nervoso completamente alterado, não podia ouvir ninguém a falar para mim sequer, o trânsito, o stresse de estar parada, o stresse com os horários..." (Mulher, motorista há 9 anos).

"Eu preferi ficar escalada pelos horários porque no "fora-de-regras" o nome já diz tudo: não há regras. Eu vinha de manhã, fazia meia viagem e ia-me embora, depois de ter acordado cedo, de madrugada, tinha 3, 4, 5 horas de intervalo, à noite vinha mais um bocadito e ia-me embora. Conclusão: eu tinha o dia todo para isto (...) Mas se aqui nesta empresa há a opção de a gente poder escolher, eu escolhi ir para escalada porque eu sei que me calha "fora-de-regras" mas há dias em que trabalho só de manhã, ou há um dia em que trabalho só de tarde. (...) Eu parece que nem trabalho porque a gente tem a metade do dia para a nossa vida pessoal e como eu tenho um filho e tudo (...) Descansa-se mais um bocadinho a cabeça porque levantar todos os dias cedo... E são horas variáveis, um dia a gente levanta-se às $4 \mathrm{~h}$, outro dia às $7 \mathrm{~h}$, porque aquilo ["fora-de-regras"] sempre, sempre, sempre, sempre, cansa um bocado." (Mulher, motorista há 1 ano).

"[Escolhi o estatuto "fora-de-regras"] para ter este intervalo na hora de almoço e chegar a casa mais cedo à noite. (...) Está bem que todos os dias me levanto mas tenho este intervalo em que posso ir a casa almoçar com a minha filha que anda na escola, adianto alguma coisa para a noite nos dias em que acabo mais tarde (...) e janto sempre com as minhas filhas." (Mulher, motorista há 1 ano).

Nestes excertos em específico, são referidas as consequências na saúde após uma permanência prolongada no desempenho dos serviços "fora-de-regras" ou a articulação da vida profissional com a vida pessoal como determinantes da opção por um estatuto, depois de terem passado pelo outro. Um dos aspectos mais referidos pelas mulheres enquanto critério de ponderação é, precisamente, a conciliação com a vida pessoal. Perante as maiores solicitações das mulheres ao nível familiar e doméstico, estas vêemse obrigadas a ponderar este interface e não só os tempos de trabalho em si. Nesta 
ponderação, as mulheres vão "experimentando", transitando entre um e outro estatuto e acabam por criar novas formas de gestão dos próprios horários de trabalho, de acordo com aquilo que lhes é imposto e com a margem de escolha que têm, numa alternância que pode ser pensada enquanto uma "variável de ajustamento" (Rodrigues, 2010), utilizada pelas mulheres ao longo do seu percurso, quando a sua vida familiar o justifica ou quando as consequências na saúde a isso obrigam. Esta alternância não se faz, contudo, sem custos para as próprias motoristas, que vêem as suas condições de trabalho alteradas e perante a necessidade de delimitar novas estratégias que se esperam que, desta vez, permitam uma conciliação mais fácil.

Em suma, nesta gestão dos horários existe uma variedade de possibilidades, que as mulheres consideram de forma particular e que as fazem recorrer a estratégias às quais os homens não recorrem, pelo menos, na mesma medida. No caso das mulheres, existe a necessidade de ponderar também a dimensão da vida pessoal e familiar, menos notória no caso dos homens, e que acaba por questionar também a organização temporal da actividade, definida tendo por base o princípio da disponibilidade total para o trabalho, própria dos modos de organização ditos masculinos. Vendo-se divididas entre a exigência de uma disponibilidade total para o trabalho e a necessidade de considerar também as exigências do interface com a vida pessoal, as mulheres questionam esta organização de uma forma que os homens não fazem e acabam por criar uma nova forma de gestão dos seus tempos, com implicações nos seus percursos profissionais, claramente distintos dos percursos dos homens.

\subsection{Mulheres polícias : a legitimação de uma nova forma de gestão da carreira}

37 No caso da polícia, o estudo foi realizado com elementos do Comando Metropolitano da Polícia de Segurança Pública do Porto. A Polícia de Segurança Pública (PSP) é uma força de segurança, uniformizada e armada, com natureza de serviço público e dotada de autonomia administrativa, que tem por missão assegurar a legalidade democrática, garantir a segurança interna e os direitos dos cidadãos, nos termos da Constituição e da lei (Lei $n^{\circ}$ 53/ 2007 de 31 de Agosto). Trata-se pois de um serviço de emergência e de apoio constante à população, o que leva a que o trabalho destes profissionais se distribua por todas as horas do dia, contribuindo, assim, para a irregularidade dos horários, mas também para disponibilidade destes profissionais para o trabalho.

\subsubsection{A organização temporal da actividade dos polícias}

Para que a PSP possa cumprir todos os seus objectivos, está definido um vasto leque de funções, cada uma delas com o seu horário de trabalho muito próprio. Grosso modo, na investigação realizada podem ser identificados quatro tipos de horários: patrulha, programas integrados de policiamento de proximidade, expediente e um quarto horário que combina um horário de expediente com um horário por turnos - trata-se do horário habitualmente desempenhado pelos polícias que se dedicam à investigação criminal, por exemplo. o horário da patrulha é caracterizado por turnos rotativos de seis horas que funcionam ao longo das 24 horas do dia, 365 dias por ano e que são atribuídos aos patrulheiros, ou seja, os que andam no carro-patrulha ou que fazem patrulha apeada. 0 horário dos polícias do Programa Integrado de Policiamento de Proximidade (PIPP [1]) alterna semanalmente entre manhãs e tardes ${ }^{[2]}$, enquanto $o$ 
horário de expediente se realiza habitualmente entre as 9 horas da manhã e as 17 ou 18 horas. Por último, existe ainda um horário que combina dias de trabalho com horário de expediente e outro de trabalho por turnos, que se relaciona com o objecto de atividade dos polícias que trabalham na investigação criminal e que, por isso, está dependente das missões realizadas por estes.

Tabela 3 - Diferentes horários de trabalho na PSP

\begin{tabular}{|c|c|c|c|c|}
\hline Tipo de horário & Patrulha & $\begin{array}{ll}\text { Programa } & \\
\text { Integrado } & \text { de } \\
\text { Policiamento de } & \text { deximidade }\end{array}$ & Expediente & Misto \\
\hline $\begin{array}{l}\text { Atribuído } \\
\text { habitualmente } \\
\text { a... }\end{array}$ & Patrulheiros & Elementos do PIPP & $\begin{array}{ll}\text { Elementos } & \text { que } \\
\text { trabalham nas } \\
\text { secretarias }\end{array}$ & \begin{tabular}{|lr} 
Elementos & que \\
trabalham & na \\
investigação criminal
\end{tabular} \\
\hline Características & $\begin{array}{l}\text { Turnos rotativos } \\
\text { de } 6 \text { horas (ao } \\
\text { longo das } 24 \mathrm{~h} \text { do } \\
\text { dia e dos } 365 \text { dias } \\
\text { do ano) }\end{array}$ & $\begin{array}{l}\text { Turnos de cerca } \\
\text { de } 6 \text { horas } \\
\text { Alternam } \\
\text { semanalmente } \\
\text { entre manhãs e } \\
\text { tardes }\end{array}$ & $\begin{array}{l}\text { De segunda a } \\
\text { sexta-feira entre } \\
\text { as } 9 \mathrm{~h} \text { e as } 17 \mathrm{~h} \text { ou } \\
\text { entre as } 9 \mathrm{~h} \text { e as } \\
18 \mathrm{~h}\end{array}$ & $\begin{array}{ll}\text { Combinam } & \text { um } \\
\text { horário habitual de } \\
\text { expediente } & \text { com } \\
\text { turnos de } & 12 \mathrm{~h} \\
\text { realizados três a } & \text { a } \\
\text { quatro vezes por mês }\end{array}$ \\
\hline
\end{tabular}

Tal como já foi referido os horários estão intimamente ligados às funções desempenhadas pelos polícias o que acaba, de alguma forma, por estar associado às opções de carreira que estes são convidados a fazer desde o primeiro momento na instituição. Estão, no entanto, habitualmente dependentes da existência de um convite ou nomeação para determinada função ou da integração numa listagem de transferência que obedece a critérios como a antiguidade ou a nota final nos vários cursos de formação existentes (eg. curso de formação de agentes que é uma das "portas de entrada" na profissão).

\subsubsection{Homens e mulheres polícias : diferentes formas de gestão dos tempos de trabalho e das opções de carreira}

Segundo os dados apresentados na figura 1, verifica-se que quase metade das mulheres do Comando Metropolitano da PSP do Porto está afecto a funções com horário de expediente. Quase um quarto das mesmas desempenha funções na patrulha e, por esse motivo, trabalha por turnos rotativos. Os restantes $29 \%$ das mulheres, estão distribuídos pelos Programas Integrados de Policiamento de Proximidade $(16 \%)$ e por funções com um outro tipo de horário (13\%). 
Figura 1 - Distribuição das mulheres polícias do Comando Metropolitano da PSP do Porto, de acordo com o tipo de horários

\section{Distribuição dos elementos femininos do Comando Metropolitano da PSP do Porto de acordo com o tipo de horários}

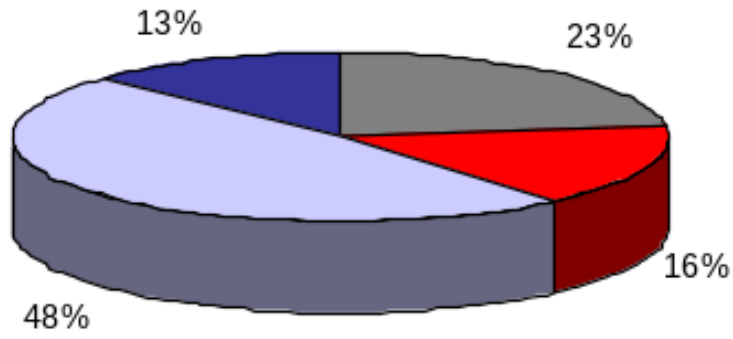

De acordo com os dados referentes às escolhas de carreira dos polícias e argumentos que as justificam, vários podem ser os motivos que levam os polícias a tomar as suas decisões : os motivos familiares, aliados à distância entre o local de trabalho e a residência, apresentam-se como aqueles que assumem um peso maior, sobretudo nas decisões das mulheres. Contudo, existem igualmente aquelas que não abdicam das funções operacionais e que, por esse motivo, enfrentam diariamente uma ginástica quase que acrobática em termos de horários, de forma a manterem a sua operacionalidade e, simultaneamente, a sua vida pessoal e familiar. Também as questões relacionadas com a saúde e a idade acabam por pesar nas decisões, sobretudo devido ao desgaste da profissão causado pelo desempenho de funções de cariz mais operacional. Este tipo de escolhas de carreira acaba por estar refletido na divisão das mulheres de acordo com os horários que exercem, tal como é visível na Figura 1.

Embora, já se vejam alguns homens com preocupações familiares, sobretudo relacionadas com os filhos, estas questões parecem pesar mais nas decisões de carreira tomadas pelas mulheres. No caso dos homens, existem igualmente outras motivações que acabam por assumir uma maior importância a esse nível, tal como surge retratado no excerto que é apresentado em seguida :

“As mulheres que eu conheço (...) na sua maioria, optaram pelos serviços administrativos porque claramente existe do outro lado a vida familiar, os homens poderá também existir essa situação de os homens também terem um bocadinho, principalmente quando têm filhos pequenos, mas julgo que não é a questão principal, eu acho que nos homens existem vários factores que condicionam ou que submetem o homem quanto a recorrer a serviços administrativos um, primeiro, a situação (...) em que a pessoa está na polícia, não por vocação mas porque, se calhar, pronto, foi uma forma, portanto, de arranjar um emprego. Esta é a primeira situação. A outra situação que existe é das pessoas estarem longe de casa (...). Fazem cento e não sei quantos quilómetros todos os dias, isso é terrível para quem mora a cento e tal quilómetros, e tem que fazer este percurso diariamente, é terrível e, se 
calhar, as pessoas acabam por deixar de lado os serviços operacionais onde poderiam ganhar mais dinheiro (...). A saúde começa, portanto, a resvalar, os problemas de saúde começam a aparecer e, por vezes, as pessoas não têm alternativa, portanto e socorrem-se, portanto, dos serviços administrativos porque é aquele que os deixa estando mais ou menos equilibrados no dia-adia, para fugirem das noites, principalmente, que só viriam agudizar esses problemas... e também existem pessoas que, pronto, por vocação própria, há serviços que existem na polícia, não precisamos de ser tacanhos a pensar dessa forma, em que há pessoas... há serviços aqui... nós temos hoje em dia, desde serviços de informática, serviços de comunicações, pessoas que antes de virem para a polícia, por vezes, já trabalhavam nesse tipo de trabalhos e, se calhar, é um local onde as pessoas continuam, portanto, a sentirem-se bem, onde continuam a se sentir úteis à polícia”. Homem, há 26 anos na PSP.

43 Esta situação pode ser justificada pelo facto de ainda serem as mulheres as que enfrentam maiores dificuldades de conciliação, devido à sua dupla ou mesmo tripla jornada de trabalho, o que acaba por ter impacto nas escolhas de carreira que fazem, tal como ilustra o seguinte excerto :

"Os horários que esse tipo de serviços praticam e que nós sabemos que, de facto, quem tem filhos, quem tem vida familiar, por vezes tem que se sujeitar um pouco, não àquilo que gostava de fazer efectivamente, mas àquilo que é possível fazer, portanto e talvez também devido a isso, é que, se calhar, na parte administrativa há uma grande maioria de mulheres, em determinados serviços, com determinados horários são a maioria de mulheres, talvez também porque os horários que se praticam nesses serviços se adequam mais a dar o apoio à família." Mulher, há 23 anos na PSP. a frequência de uma formação que permita uma ascensão na carreira, ela origina, na maioria dos casos, uma nova colocação que poderá ser longe da residência, bem como o reingresso na lista de transferências. Nos casos de mobilidade horizontal, pode ou não estar envolvida uma transferência de comando, ou seja, a mudança do local de trabalho pode não ser superior a alguns quilómetros. Não obstante, os polícias podem ainda escolher uma mobilidade horizontal que lhes permita romper com o desgaste da rua $\mathrm{e}$ encontrar benefícios ao nível dos horários, como acontece, por exemplo, quando um polícia passa a assumir funções mais de tipo burocrático, como seja o trabalho nas secretarias das esquadras que permite dar apoio logístico ao funcionamento operacional da mesma.

Alguns dos polícias optam por mudar para funções com horários mais compatíveis, na altura do nascimento dos filhos, acabando por gostar dessas mesmas funções e até se acomodar a elas. Aliás, de acordo com Durão (2008), os polícias que deixam a rua e as funções operacionais, dificilmente regressam. Veja-se o exemplo desta mulher que optou por serviços administrativos quando o filho nasceu e que quando questionada sobre a possibilidade de regressar à patrulha responde: "Quando o filhote for mais velho, agora já não é pela idade dele, agora é pela minha, não é?" (Mulher, há 21 anos na PSP). Assim, verifica-se que os esforços para estabelecer as regulações entre o tempo passado no trabalho e fora dele pode exigir algumas alterações a nível da própria gestão do percurso profissional das mulheres, nomeadamente a opção por uma carreira específica, colocar a sua carreira "em espera" enquanto as crianças são pequenas quando as dificuldades de conciliação se mostrem mais difíceis (Caroly, 2009). 

proprias evoluções dos sectores e das profissões em que se encontram, estas mulheres acabam também por construir percursos profissionais distintos dos homens. No caso das mulheres motoristas, distintos em relação a gerações de motoristas homens mais antigos, que rapidamente progrediam para estatutos com horários mais favoráveis e para quem a permanência em estatutos mais penosos se apresentava como uma imposição "transitória", em vez de uma opção (ainda que constrangida) com efeitos mais permanentes. Já no caso da polícia, a construção de percursos profissionais alternativos por parte das mulheres acaba por se constituir como uma ferramenta de gestão de carreira e também da diminuição da "invasão" que as responsabilidades profissionais, não raras vezes, fazem dos seus tempos sociais. 
51 Esta pesquisa permite-nos perceber, por um lado, como o processo de feminização das profissões desencadeia transformações e evoluções nas actividades de trabalho pelo modo como são ponderadas, organizadas e estruturadas prioridades, desempenhando as mulheres um importante papel na provocação de discussões e reflexões e, especificamente, na legitimação de opções de gestão de tempo e de carreira que, até então, não eram utilizadas pelos seus colegas. Por outro lado, em alguns casos, ao abdicarem de uma carreira mais favorável em prol de uma disponibilidade possível, que permita uma mais fácil conciliação, as mulheres transformam a gestão quotidiana do tempo numa gestão de carreira e colocam em questão o valor diferenciado do tempo disponível para o trabalho e da progressão profissional. Mais do que isso, trazem a debate uma discussão referida por Alaluf (2000), pertinente nos nossos dias e comum a diversos sectores de actividade - num contexto de crescente flexibilização dos tempos de trabalho, será que a procura de alguém disponível para trabalhar em determinados regimes de organização temporal do trabalho tenderá a sobrepor-se à procura de características profissionais e competência superior e, nesse sentido, o tempo passará a assumir, cada vez mais, um valor mercantil?

Notas

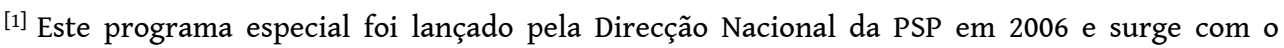
objectivo de congregar os vários projectos que foram surgindo até então - ex. Idosos em segurança, comércio seguro. O maior enfoque deste programa é feito na componente de proximidade/ prevenção da criminalidade e na melhoria da sua articulação com as componentes de ordem pública, investigação criminal e informações policiais.

[2] Por norma contempla também alguns turnos nocturnos que são realizados de forma alternada pelos elementos que fazem parte do PIPP. Em algumas missões poderão igualmente existir alterações ao regime normal dos turnos do PIPP.

\section{Referências bibliográficas}

Alaluf, M. (2000). Le travail du temps. In Gilbert de Terssac \& Diane-Gabrielle Tremblay (Dirs.), Oú va le temps de travail ? (pp. 203-213). Toulouse : Octarés Éditions.

Barros-Duarte, C., Cunha, L., \& Lacomblez, M. (2007). INSAT : uma proposta metodológica para análise dos efeitos das condições de trabalho sobre a saúde. Laboreal, 3, (2), 54-62. http://laboreal.up.pt/revista/artigo.php?id=37t45nSU547112311:499682571

Barthe, B., \& Abbas, L. (2009). Atypical work schedules and gender : new questions for ergonomics? Proceedings IEA 2009 : Changes, Challenges and Opportunities, China.

Burchielli, R., Bartram, T., \& Thanacoody, R. (2008). Work-family Balance or Greedy Organizations? Relations Industrielles/Industrial Relations, 63, (1), 108-133.

Caroly, S. (2009). How police officers and nurses regulate their combined domestic and paid workloads to manage their schedules: a gender analysis. Proceedings IEA 2009: Changes, Challenges and Opportunities, China.

Copsey, S., \& Schneider, E. (2008). OSH and the transport sector. Barents Newsletter on Occupational Health and Safety, 11, 39.

Cunha, L. \& Gil Mata, R. (2005). Organização do Trabalho e Saúde Ocupacional no Sector dos Transportes: um contributo para a transformação das condições da actividade profissional dos motoristas. Porto : Faculdade de Psicologia e de Ciências da Educação da Universidade do Porto. 

Messing, K. (2000). Compreender o trabalho das mulheres para o transformar : uma
investigação/ acção realizada pela Universidade e pelas organizações sindicais do Quebeque. In Karen Messing (Ed.), Compreender o Trabalho das Mulheres para o Transformar (pp. 51-74). Lisboa : CITE.

Cunha, L. (2012). Mobilidades, territórios e serviço público : debates sobre o interesse colectivo á margem do paradigma de uma sociedade móvel. Tese de Doutoramento, Faculdade de Psicologia e de Ciências da Educação da Universidade do Porto, Porto.

Cunha, L., Nogueira, S., \& Lacomblez, M. (2012). Thinking about gender, thinking about a common space of observation and discussion of the work activity of the other : the case of bus drivers. Work, 41, 4297-4301.

Durão, S. (2008). Patrulha e proximidade: uma etnografia da polícia em Lisboa. Coimbra, Portugal : Almedina.

Grönkvist, L., \& Lagerlöf, E. (2000). A saúde e o trabalho das mulheres europeias. In Karen Messing (Ed.), Compreender o Trabalho das Mulheres para o Transformar (pp. 35-50). Lisboa : CITE.

Grozelier, A.-M. (1987). Le travail des femmes. In Jean-Claude Sperandio \& Claude LevyLeboyer (Orgs.),. Traité de psychologie du travail (pp. 261-287). Paris : PUF.

Guichard-Claudic, Y., Kergoat, D., \& Vilbrod, A. (Dirs.) (2008). L'inversion du genre. Quand les métiers masculins se conjuguent au féminin... et réciproquement. Rennes, France : PUR.

Hirata, H., Lombardi, M. R., \& Maruani, M. (Dirs.) (2008).Travail et genre. Regards croisés : France Europe Amérique Latine. Paris : Édition La Découverte.

http://laboreal.up.pt/revista/artigo.php?id=48u56oTV6582234396;;2493:32

Kergoat , D. (1993). Des hommes, des femmes et du travail. Éducation Permanente, 116, 133-139.

Lacomblez, M. (2008). A feminização dos meios de trabalho definidos em masculinidade : debates de normas e desenvolvimento. Laboreal, 4, (1), 39-45.

Lopes, M. C. \& Perista, H. (2010). Trinta anos de educação, formação e trabalho: convergências e divergências nas trajectórias de mulheres e homens. In Virgínia Ferreira (Org.), A igualdade de Mulheres e Homens no Trabalho e no Emprego em Portugal: Políticas e Circunstâncias (pp. 191-216). Lisboa : Comissão para a Igualdade no Trabalho e no Emprego.

Martinez, E. (2010). Les salariés à l'épreuve de la flexibilité. Bruxelles, Belgique : Editions de l'Université de Bruxelles.

Maruani, M. (2007). Tiempo, trabajo y género. In Carlos Prieto (Ed.), Trabajo, género y tiempo social (pp. 85-91). Madrid/Barcelona : Editorial Complutense/Editorial Hacer. Messing, K. (2000). Compreender o trabalho das mulheres para o transformar : uma
investigação/ acção realizada pela Universidade e pelas organizações sindicais do

Monteiro, R. (2010). Genealogia da lei da igualdade no trabalho e no emprego desde finais do Estado novo. In Virgínia Ferreira (Org.), A igualdade de Mulheres e Homens no Trabalho e no Emprego em Portugal : Políticas e Circunstâncias (pp. 31-56). Lisboa, Portugal : Comissão para a Igualdade no Trabalho e no Emprego.

77 Perista, H. (1999). Trabalho, família e usos do tempo - Uma questão de género. Sociedade e trabalho, 6, 69-74.

78 Perista, H. (2002). Género e trabalho não pago : os tempos das mulheres e os tempos dos homens. Análise Social, XXXVII (163), 447-474. 


\section{NOTAS}

1. Este programa especial foi lançado pela Direcção Nacional da PSP em 2006 e surge com o objectivo de congregar os vários projectos que foram surgindo até então - ex. Idosos em segurança, comércio seguro. o maior enfoque deste programa é feito na componente de proximidade/ prevenção da criminalidade e na melhoria da sua articulação com as componentes de ordem pública, investigação criminal e informações policiais. 
2. Por norma contempla também alguns turnos nocturnos que são realizados de forma alternada pelos elementos que fazem parte do PIPP. Em algumas missões poderão igualmente existir alterações ao regime normal dos turnos do PIPP.

\section{RESUMOS}

O tempo assume-se como uma questão central na (des)igualdade entre homens e mulheres no trabalho, sendo particularmente visível na forma como distribuem o seu tempo diariamente. Em profissões tipicamente masculinas, onde a organização temporal segue o pressuposto da disponibilidade total para o trabalho, os tempos são mais suscetíveis de dificultar a conciliação com a vida pessoal, sobretudo para as mulheres, as maiores responsáveis pelas tarefas na esfera doméstica.

A realização de dois estudos de caso com polícias e motoristas, profissões em processo de feminização, permitiu dar conta do papel central do fator tempo nestas atividades. Em ambos, a articulação trabalho/família num quadro de horários atípicos depende da mobilização de estratégias distintas para homens e mulheres. No caso destas, uma diferente gestão dos tempos de trabalho diários corresponde também a uma gestão diferenciada da carreira profissional.

Os resultados encontrados possibilitam uma reflexão acerca do contributo das mulheres para estas atividades, questionamentos e debates que desencadeiam no que concerne, sobretudo, a organização temporal do trabalho mas também o valor do tempo no mercado de trabalho atual.

Se asume al tiempo como una cuestión central en la (des)igualdad entre hombres y mujeres en el trabajo, haciéndose particularmente visible en la forma en la que distribuyen su tiempo a diario. En las profesiones típicamente masculinas, donde la organización temporal parte del supuesto de una disponibilidad total para el trabajo, los tiempos son más propensos a obstaculizar la conciliación con la vida personal, especialmente para las mujeres, mayormente responsables de las tareas en el ámbito doméstico.

La realización de dos estudios de caso, con la policía y los conductores, ambas profesiones en el proceso de feminización, permitió dar cuenta de la función central del factor tiempo en estas actividades. En los dos casos, la conciliación trabajo/ familia en contexto de horarios atípicos de trabajo depende de la movilización de estrategias diferentes para hombres y mujeres. Para las mujeres, un manejo diferente del tiempo de trabajo diario se corresponde también con una gestión diferenciada de carrera.

Los resultados obtenidos permiten a una reflexión sobre la contribución de las mujeres a estas actividades, cuestionamientos y debates que referien, sobre todo la organización temporal del trabajo, pero también al valor del tiempo en el mercado de trabajo actual.

Le temps est une question centrale dans l' (in) égalité entre hommes et femmes dans le travail, étant particulièrement visible dans la façon dont les uns et les autres distribuent le temps dans le quotidien. Dans les métiers typiquement masculins, où l'organisation temporelle est basée sur le présupposé de la disponibilité totale pour le travail, les temps sont davantage susceptibles de rendre difficile la conciliation avec la vie personnelle, surtout pour les femmes qui assurent l'essentiel des tâches domestiques.

La réalisation de deux études de cas, menés dans le cadre de métiers en cours de féminisation, l'une avec des policiers et l'autre avec des conducteurs de bus, a permis de rendre compte du rôle 
central joué par le temps dans ces activités. L'articulation travail/ famille dans le cas des horaires atypiques exige la mobilisation de stratégies qui sont distinctes pour les hommes et les femmes. Et pour celles-ci, elles sont associées à une gestion différenciée du parcours professionnel.

Les résultats permettent une réflexion concernant la contribution des femmes dans ces activités, questionnements et débats qui concernent surtout l'organisation temporelle du travail mais aussi l'importance du temps sur le marché du travail actuel.

Time presents itself as a central issue in the (in)equality between men and women at work, being particularly noticeable in the way they distribute their time daily. In typically male professions, where the temporal organization follows the assumption of total availability to work, the schedules are more likely to hamper reconciliation with the personal life, especially for women, as they are primarily responsible for the tasks in the domestic sphere.

The completion of two case studies with police officers and bus drivers, professions undergoing a process of feminization, highlighted the central role of the factor time in these activities. In both cases, the reconciliation work / family in an atypical schedules context depends on the mobilization of different strategies for men and women. In the case of women, a different management of daily work time also corresponds to a different way of managing their career.

The results enable a reflection on the contribution of women to these activities, the questions and the discussions that they trigger regarding, especially, the temporal organization of work but also the value conferred to time in the current labor market.

\section{ÍNDICE}

Mots-clés: temps, féminisation, horaires de travail, parcours professionnel

Palabras claves: tiempo, feminización, horarios de trabajo, carrera

Palavras-chave: tempo, feminização, horários de trabalho, percurso profissional

Keywords: time, feminization, working schedules, career path

\section{AUTORES}

\section{SÓNIA NOGUEIRA}

Centro de Psicologia da Universidade do Porto, Rua Alfredo Allen, 4200-135 Porto, Portugal snogueira@fpce.up.pt

\section{JOANA CASTELHANO}

Centro de Psicologia da Universidade do Porto, Rua Alfredo Allen, 4200-135 Porto, Portugal jcastel@fpce.up.pt 